\title{
Effects of a progestogen on normal human breast epithelial cell apoptosis in vitro and in vivo
}

\author{
J. Desreux, ${ }^{1}$ F. Kebers, ${ }^{1}$ A. Noël, ${ }^{1}$ D. Francart, ${ }^{1}$ H. Van Cauwenberge, ${ }^{1}$ V. Heinen, ${ }^{1}$ K. Peyrollier, ${ }^{1}$ J. L. Thomas, ${ }^{2}$ \\ A. M. Bernard, ${ }^{2}$ J. Paris, $^{2}$ R. Delansorne ${ }^{2}$ and J. M. Foidart ${ }^{1}$ \\ ${ }^{1}$ Laboratory of Tumor and Development Biology, University Hospital, University of Liège, Sart Tilman, B-4000 Liège, Belgium \\ ${ }^{2}$ Theramex Laboratories, Monaco
}

\begin{abstract}
SUMMARY
Many investigators have reported cyclic proliferation of normal human breast epithelial cells. A delicate balance between proliferation and apoptosis (programmed cell death) ensures breast homeostasis. Both the follicular and luteal phases of the menstrual cycle are characterized by proliferation, whereas apoptosis occurs only at the end of the latter phase. In this study, we observed that the withdrawal of a synthetic progestin (nomegestrol acetate or NOMAC), but not continuous treatment with it, induced apoptosis of normal human breast epithelial cells in vitro and in women who applied NOMAC gel to their breasts. Furthermore, this apoptotic response was specific to normal breast cells, since withdrawal of NOMAC did not induce apoptosis of tumoral T47D cells in vitro or of fibroadenoma cells in women. These observations open up new perspectives in the prevention of hyperplasia and breast cancer.
\end{abstract}

Keywords: normal breast ; fibroadenoma ; breast cancer ; apoptosis ; progestogen ; nomegestrol acetate

\section{INTRODUCTION}

It is essential that cell number be controlled during processes involving the renewal of tissues in both embryos and adults. This control relies on a delicate balance between proliferation and cell death. Proliferation and apoptosis (programmed cell death) have indeed been implicated in several normal processes, such as tissue development and homeostasis, but also in certain pathologic states. ${ }^{1,2}$

In the 'resting' human breast, epithelial cell proliferation has been reported to peak during the follicular ${ }^{3,4}$ and luteal phases of the menstrual cycle. ${ }^{5-8}$ On the other hand, Ferguson and Anderson, in 1981, noted the highest percentage of apoptotic cells during menstruation. ${ }^{5}$ The expression of Bcl-2, which inhibits apoptosis, ${ }^{9}$ is maximal in breast epithelial cells during ovulation and then declines dramatically as the number of cells affected by apoptosis rises. ${ }^{10}$ This sequence of events suggests that Bcl-2 expression and apoptosis are directly or indirectly influenced by ovarian steroid hormones. ${ }^{11-13}$ The premenstrual period is characterized by a rapid decrease of serum levels of progesterone. Therefore, in the present study, we examined the effects of a progestin (17 $\alpha$-acetoxy-6-methyl-nor-pregna-4,6-diene-3,20-dione: nomegestrol acetate, NOMAC, LUTENYLTM) on the apoptosis of normal breast epithelial cells, both in vitro and in vivo. NOMAC, a 19-norprogesterone derivative, lacks estrogenic activity, as demonstrated by estrogen receptor-binding assays, growth assays using MCF-7 and T47D:A18 cells, and transient transfection studies. ${ }^{14}$ Its half-life, which is longer than 3 days in the culture medium of T47-D cells, ${ }^{15}$ affords highly steady-state concentrations if the medium is renewed daily.

In addition, to determine whether the apoptotic process could be modified in the context of a pathologic condition, we also evaluated the responses to this progestin of T47D breast epithelial tumor cells in vitro and of epithelial cells of fibroadenomas in vivo.

\section{MATERIALS AND METHODS}

\section{In vitro studies}

Cell cultures

Human mammary epithelial cells (HMECs) were isolated from tissues obtained from reduction mammoplasties and processed immediately after surgery as previously described. ${ }^{16}$ Primary cultures were grown in DMEM/F12 (GIBCO), $5 \%$ fetal calf serum (FCS), $0.5 \mu \mathrm{g} / \mathrm{ml}$ of hydrocortisone (Sigma), $10 \mu \mathrm{g} / \mathrm{ml}$ of insulin (Sigma), 0.05 $\mu \mathrm{g} / \mathrm{ml}$ of cholera toxin (Sigma), $5 \mu \mathrm{g} / \mathrm{ml}$ of EGF (Sigma), and $100 \mathrm{IU} / 100 \mu \mathrm{g} / \mathrm{ml}$ of penicillin/ streptomycin (Sigma). The culture medium was changed every 3 days, and the primary cells used in the experiment were harvested after one trypsinization of 15-day-old cultures. The epithelial nature of the cells was confirmed in antikeratin 8-18 antibody (Beckton-Dickinson) labeling studies. The human mammary tumor cell line T47D was obtained from American Type Cell Culture and cultured in RPMI 1640 medium (Gibson), 10\% FCS, 100 IU/100 $\mu \mathrm{g} / \mathrm{ml}$ of penicillin/ streptomycin according to ATCC recommendations. 


\section{Hormonal treatments}

The primary cultures of HMEC (15000 cells/well) and T47D cells (10000 cells/well) were seeded on plastic coverslips (Thermanox). After $48 \mathrm{~h}$, the medium was replaced with fresh steroid-free medium (without red phenol) supplemented with dextran-charcoal-treated serum until half-confluency was reached (50\% saturation). Cells were then cultured in three different conditions: (A) in a steroid-free medium containing $0.1 \%$ ethanol for 6 days; (B) in the presence of steroid-free medium containing $10^{-7} \mathrm{M}$ NOMAC dissolved in $0.1 \%$ ethanol, with the medium changed once a day; $(\mathrm{C})$ in the presence of steroid-free medium containing $10^{-7} \mathrm{M}$ NOMAC dissolved in $0.1 \%$ ethanol for 3 days, and subsequently in the same medium but with no NOMAC. The medium was replaced every $24 \mathrm{~h}$ and the cultures were arrested 6, 12, 18, 24, 30, 36 or $42 \mathrm{~h}$ after NOMAC withdrawal.

\section{In situ detection of apoptosis}

Terminal dUTP nick-end labeling (TUNEL) ${ }^{17}$ was used to detect free 3 '-end OH groups in situ in fragmented DNA according to the manufacturer's instructions (In Situ Cell Death Detection Kit, Boehringer Mannheim), albeit with some modifications: cultures were fixed in $4 \%$ paraformaldehyde in phosphate-buffered saline (PBS) at room temperature for $15 \mathrm{~min}$ and permeabilized with ice-cold methanol at $-20^{\circ} \mathrm{C}$ for $10 \mathrm{~min}$. Cells were rinsed with 70\% ethanol, rehydrated twice with PBS for $10 \mathrm{~min}$, and incubated with the TUNEL reaction mixture (containing terminal deoxynucleotidyl transferase and fluorescein-labeled low-molecular-weight DNA fragments) for $1 \mathrm{~h}$. Apoptotic cells were revealed by alkaline phosphatase-coupled anti-fluorescein antibody (provided in the kit), and New Fuchsine Substrate System (Dako). Cells were counterstained with hematoxylin and eosin. Apoptotic (red nucleus) and viable (blue nucleus) cells were counted for each culture condition. Automated quantitative immunolabeling analysis was performed using a computer-assisted image processor (CAS 200), as previously described. ${ }^{18}$ At least 1000 nuclei were counted for each well. Appropriate positive controls (HMEC incubated with Dnase I to induce strand breaks) and negative controls (HMEC incubated with fluorescein-labeled DNA fragments without terminal transferase) were included.

\section{Caspase-3 activity}

Caspase-3 (Yama/apopain/CPP32) is an enzyme similar to interleukin $1 \beta$-converting enzyme that is implicated in apoptosis. ${ }^{19,20}$ Its activity was measured as previously described. ${ }^{20}$ HMEC or T47-D were plated onto $85-\mathrm{mm}$ diameter dishes and grown to $75 \%$ confluence $\left(2.5 \times 10^{6}\right.$ cells). After hormone treatment, they were rinsed in PBS, detached by scraping, and placed on ice for $2 \mathrm{~h}$ in lysis buffer containing protease inhibitors [50 mM Tris, pH 7.4, 1 mM ethylenediamine tetraacetic acid (EDTA), $10 \mathrm{mM}$ ethylene glycol tetraacetic acid (EGTA), and $0.2 \mathrm{mM}$ phenylmethylsulfonyl fluoride (PMSF)]. Cell lysates were then centrifuged at $1500 \mathrm{~g}$ for $10 \mathrm{~min}$, and supernatants were collected and kept on ice. The protein concentration was adjusted to $90 \mu \mathrm{g} / \mathrm{ml}$ in AFC-120 buffer [50 mM HEPES ( $N$-2-hydroxyethylpiperazine-N'-2-ethane sulfonic acid) pH 7.5, 1\% sucrose, 0.1\% CHAPS (3-[(3-cholamidopropyl)dimethylammonio]-1-propanesulfonate)]. Dithiothreitol was added to give a final concentration of $10 \mathrm{mM}$. Caspase-3 fluorogenic substrate Ac-DEVD-AFC ( $N$-acetyl-Asp-Glu-Val-AspAFC, Enzyme Systems Products) was diluted in $2.5 \mathrm{mM}$ DMSO and added to samples (final concentration 50 $\mu \mathrm{M})$. Fluorescence changes were monitored with a Perkin-Elmer MPF-44B fluorescence spectrophotometer (excitation wavelength: $400 \mathrm{~nm}$; emission wavelength: $505 \mathrm{~nm}$ ) at various times over $32 \mathrm{~h}$. Lysates of freshly isolated or overnight-cultured murine lymphocytes were used as negative and positive controls, respectively. ${ }^{21}$ Each measure was done in triplicate.

\section{Caspase-3 inhibition}

The caspase-3 inhibitor Ac-DEVD-CHO ( $N$-acetyl-Asp-Glu-Val-Asp-CHO(aldehyde), Enzyme Systems Products) was added to the medium $(50 \mu \mathrm{l} / \mathrm{ml}$ of medium) at the same time as NOMAC was withdrawn. Cells were fixed and analyzed using the TUNEL technique described above. Each measurement was done in triplicate.

\section{SDS-PAGE and immunoblotting}

After two or four trypsinizations, HMEC were cultured and treated with NOMAC for 3 days in steroid-free medium as described above. Those cells were then lysed (50 $\mu \mathrm{g}$ protein) and subjected to SDS-PAGE and immunoblotting as described previously. ${ }^{22}$ Separated proteins were transferred onto microporous polyvinylidene fluoride membranes (NEN, USA) and blocked with Tris-buffered saline containing $3 \%$ of bovine serum albumin (BSA). Membranes were probed with rabbit anti-human progesterone-receptor type B (PR-B) (DAKO, Denmark). Following primary antibody incubation, membranes were washed and then incubated with peroxidase conjugated swine anti-rabbit immunoglobulins (DAKO). Immunoreactive protein bands were visualized by enhanced chemiluminescence on Kodak medical film. T47D cells were included for positive controls, and skin fibroblasts (kindly provided by Dr Charlie Lambert, Laboratory of Biology of Connective Tissues, CHU of Liège), for negative controls. 


\section{In vivo studies}

\section{Patients}

The study was designed as a prospective, randomized, double-blind trial. Forty premenopausal women (mean age $32.8 \pm 11.6$ years, range 16-53 years) with documented spontaneous regular menstrual cycles were enrolled in this study. Previous hormonal contraception was discontinued. Twenty of these women had requested a reduction mammoplasty and had no known breast pathology (normal breast group). The others underwent removal of a fibroadenoma, which had been diagnosed clinically and radiologically and confirmed histologically (fibroadenoma group). In each group, the women were randomly and blindly assigned to one of two treatment groups and received a hydro-alcoholic gel (2 g/day) containing either NOMAC 2.2 g/day or a placebo. Each gel formulation was applied daily to both breasts for 14 days prior to surgery, from the first to the 14th $( \pm 1)$ day of the menstrual cycle. Surgery was performed on the 15th day of the menstrual cycle. The study design was approved by the University of Liège Ethics Committee, and oral informed consent was obtained from each woman.

\section{Study design}

Surgery was performed on the 15th day of the menstrual cycle, before exposure to endogeneous progesterone produced by the corpus luteum during the postovula \pm tory phase of the cycle. The gel was applied for the last time 24-30 h before surgery. During surgery, a blood sample was taken for plasma level measurements of estradiol ( $\left.E_{2}\right)$, progesterone (P) (DPC Diagnostic Products), and sex hormone-binding globulin (SHBG) (Biocode). The absence of ovulation was verified by measurement of the plasma levels of progesterone which remained below 6-20 ng/ml. The presence of comparable values for SHBG in each of the four test groups is indicative of tissue exposure to comparable levels of endogenous estrogens, which are known to regulate progesterone receptor expression. The plasma levels of estradiol did not differ significantly in the four groups tested but showed considerable interindividual variation (Table 1). The women were thus exposed predominantly to the synthetic progestin or to placebo. Plasma NOMAC levels were measured by SPI/BIO (Gif-sur-Yvette, France). Two samples of normal breast tissue or fibroadenoma were set aside for this study. The first was stored at $-20^{\circ} \mathrm{C}$ and processed for measurement of the tissue concentrations of $\mathrm{E}_{2}$ and NOMAC using a specific RIA already described elsewhere. ${ }^{18}$ The second sample was fixed and used for semi-quantitative evaluation of estradiol receptors (ERs) and progesterone receptors (PRs) using ER-RIA and PR-RIA kits (Abbott Diagnostics Division) and for detection of apoptosis by TUNEL, as described above except for the following modifications. Tissue sections were deparaffinized, rehydrated, and incubated with proteinase $\mathrm{K} 10 \mu \mathrm{g} / \mathrm{ml}$ in Tris/ $\mathrm{HCl}$ for 10 min at room temperature, and then with the TUNEL mixture for $1 \mathrm{~h}$ at $37^{\circ} \mathrm{C}$. Slides were then incubated with peroxidase-coupled anti-fluorescein antibody (provided in the kit). Labeling was revealed by diaminebenzimide and slides were counterstained with methyl green (Sigma). Appropriate positive and negative controls were included. Semi-automated quantitative immunolabeling analysis was performed on a computer-assisted image processor (CAS 200) as described above. At least 2000 nuclei from the luminal epithelial and myoepithelial layers of the ducts and alveoli were evaluated for each tissue sample. All analyses were performed blind before the trial code was opened. All the patients whose histological examinations did not confirm their normal breast or fibroadenoma status were excluded from the study.

Table 1 Plasma and tissue hormone levels as a function of breast pathology

\begin{tabular}{lcccc}
\hline & \multicolumn{3}{c}{ Fibroadenoma } \\
\cline { 2 - 5 } & Placebo $(n=6)$ & NOMAC $(n=6)$ & Placebo $(n=7)$ & NOMAC $(n=6)$ \\
\hline Plasma & $30.9 \pm 33.8$ & $38.9 \pm 51.4$ & $70.4 \pm 80$ & $52 \pm 32$ \\
Estradiol (pg/ml) & $2.7 \pm 4.5$ & $1.1 \pm 1.3$ & $2.6 \pm 3.6$ & $3.2 \pm 6$ \\
Progesterone (ng/ml) & $76.2 \pm 79.4$ & $73.8 \pm 32.9$ & $103 \pm 77.7$ & $62.8 \pm 22.7$ \\
SHBG (pM/ml) & BDL & $0.39 \pm 0.38$ & BDL & $0.38 \pm 0.27$ \\
NOMAC (ng/ml) & & & & $0.19 \pm 0.07$ \\
Tissue & $0.12 \pm 0.04$ & $0.14 \pm 0.04$ & BDL & $0.38 \pm 0.25$ \\
Estradiol (ng/g) & BDL & $1.06 \pm 0.57$ & & 0.12 \\
NOMAC (ng/g) & & &
\end{tabular}




\section{RESULTS}

\section{In vitro studies}

The primary cultures of HMEC remained viable and expressed PR as documented by SDS-PAGE and immunoblotting (Fig. 1).

Apoptosis was evaluated using the TUNEL technique, in HMEC cultured continuously with a synthetic progestin, nomegestrol acetate (NOMAC), and at various time points after it had been withdrawn from the culture medium. Untreated control cells showed a low and constant level of apoptosis ( $8 \pm 5 \%$ cells; $n=4)$. Similarly low levels of apoptosis ( $9 \pm 6 \%$ cells; $n=4)$ were observed when cells were exposed to $10^{-7} \mathrm{M}$ NOMAC continuously for $72 \mathrm{~h}$. In contrast, the rate of apoptotic cells ranged between $3 \pm 1 \%$ and $7 \pm 5 \%$ cells 6 and 12-18 h respectively after progestin withdrawal, but subsequently increased dramatically reaching $41 \pm 14 \%$ $(n=4)$ after $24 \mathrm{~h}$ of hormonal deprivation. The proportion of cells undergoing apoptosis subsequently returned to low levels comparable to those in control cultures $(9 \pm 6 \% ; n=4$, untreated cells or cells subjected to continuous treatment) (Fig. 2).

For further characterization of the biochemical characteristics of the apoptotic response, caspase-3 activity was analyzed in cell lysates by using a specific fluorigenic substrate. The cascade of caspases is an autocatalytic cascade of proteases, which are responsible for the final steps of apoptosis. Caspase 9, the first step, activates caspase-3 (CPP32), which acts as a protease on some components of the cytoskeleton and a DNA-repairing enzyme (PARPP). Caspase-3 activity was consistently higher in cultures from which NOMAC had been withdrawn $24 \mathrm{~h}$ before than in untreated control cultures or cultures exposed to NOMAC continuously (Fig. 3).

We therefore tested the effect of a caspase-3 inhibitor on the apoptosis of cells from which NOMAC had been withdrawn. When the caspase-3 inhibitor DEVD-CHO was added to the culture medium at the time of progestin withdrawal, apoptosis remained at control levels, as assessed by TUNEL (Fig. 2). As expected, this caspase-3 inhibitor did not affect cell apoptosis either under control or under continuous NOMAC conditions (data not shown).

Fig. 1 Expression of PR detected by SDS-PAGE and immunoblotting in HMECs cultured in the conditions used to show the apoptosis peak, after two (lane 3) or four passages (lane 4). T47D cells were used as a positive control (lane 1) and skin fibroblasts, as a negative control (lane 2). Expression of PR in HMEC was maintained in significant amounts after multiple trypsinizations and 3 days of NOMAC treatment $\left(10^{-7} \mathrm{M}\right)$.

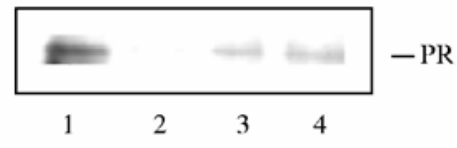

Absence of NOMAC-induced apoptosis in tumoral breast T47D cells

To determine whether or not this apoptotic response to NOMAC withdrawal was specific to normal epithelial cells, human breast adenocarcinoma T47D cells expressing PR (demonstrated by SDS-PAGE immunoblotting as mentioned above) were subjected to NOMAC treatment and its withdrawal, and apoptosis was evaluated using the TUNEL technique and measurement of caspase-3 activity. Unlike the HMEC affected by apoptosis, T47D stained by the TUNEL technique and therefore apoptotic still accounted for under $1 \pm 0.5 \%$ of all T47D cells $(n=4) 24 \mathrm{~h}$ after NOMAC withdrawal (Fig. 4), and caspase-3 activity also did not rise in the same conditions (Fig. 3). These findings suggest that the influence of progestin withdrawal on apoptosis observed in vitro is specific to normal mammary epithelial cells.

\section{In vivo studies}

Women with no known pathology (normal breast group) who had requested reduction mammoplasty and women undergoing fibroadenoma removal (fibroadenoma group) were enrolled in the present in vivo study. Only 25 (12 in the normal breast group and 13 in the fibroadenoma group) of the 40 women initially enrolled completed the study. Most of the other 15 were excluded because of protocol irregularities. In the normal breast group, six patients received the NOMAC gel and six received the placebo gel. In the fibroadenoma group, six applied the NOMAC gel and 7 the placebo gel. The plasma levels of $E_{2}, P, S H B G$, and NOMAC are shown in Table 1 and did not vary significantly among the groups. 


\section{In situ apoptosis detection}

Apoptosis was detected in breast sections using the TUNEL technique. The stromal cells of normal breast tissue or fibroadenoma did not differ significantly in their apoptosis levels, regardless of the treatment. The epithelial cells of NOMAC-treated normal breast exhibited significantly $(P<0.01)$ higher levels of apoptosis than the corresponding placebo-treated cells (Table 2). In fibroadenomas, the rate of epithelial cell apoptosis was higher than in normal breast but did not vary according to breast exposure to progestin (Table 2).

Fig. 2 HMEC apoptosis after NOMAC withdrawal and effect of caspase-3 inhibitor DEVD-CHO. Cells cultured as described in the 'Materials and methods' section were untreated $(\bullet)$, were continuously treated with NOMAC (-), or had NOMAC withdrawn at $0 \mathrm{~h}(\mathbf{\Delta})$. Caspase-3 inhibitor was able to block the apoptotic response observed after NOMAC withdrawal ( $\bullet$. Apoptosis was detected by means of the TUNEL technique. Individual values shown are mean + standard deviation in four cultures in a representative experiment. Each experiment was repeated at least 4 times with HMEC from different women, with consistent findings.

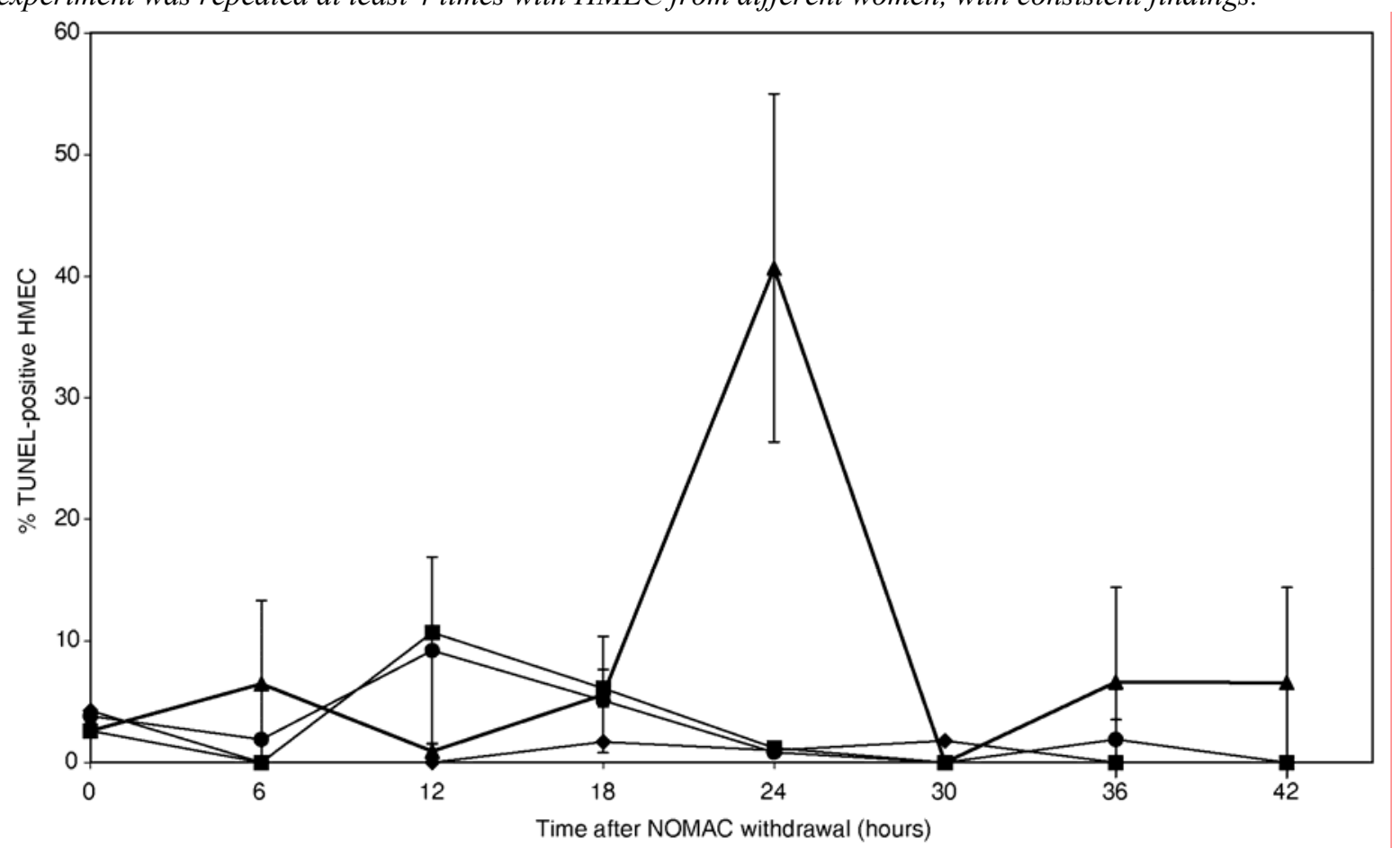

Table 2 Number of TUNEL-positive cells per thousand cells as a function of breast pathology (expressed in medians and range)

\begin{tabular}{lllll}
\hline & \multicolumn{3}{l}{ Normal breast } & Fibroadenoma \\
\cline { 2 - 5 } & Placebo & NOMAC & Placebo & NOMAC \\
\hline Epithelial cells & $19.97(10.8-36)$ & $53.7(30.8-63)^{*}$ & $69.1(53.8-79.1)$ & $60.7(41.6-89.4)$ \\
Stromal cells & $65.4(53.5-71.5)$ & $50.5(35.2-61)$ & $56.4(32.9-84.6)$ & $66.4(13.1-79.6)$ \\
\hline
\end{tabular}

* Significantly different $(P<0.01)$ from the placebo group (Student's $t$-test). 
Fig. 3 Effect of NOMAC withdrawal or continuous treatment on apoptosis in HMEC and T47D tumor cells, assessed by measurement of caspase-3 activity. Cells cultured as described in the 'Materials and methods' section remained untreated, were treated with NOMAC administered daily or were initially treated with NOMAC, which was withdrawn after $24 \mathrm{~h}$. This method of evaluation confirmed the peak of apoptosis induced 24 h after withdrawal of NOMAC in HMEC, but not in T47D cells.

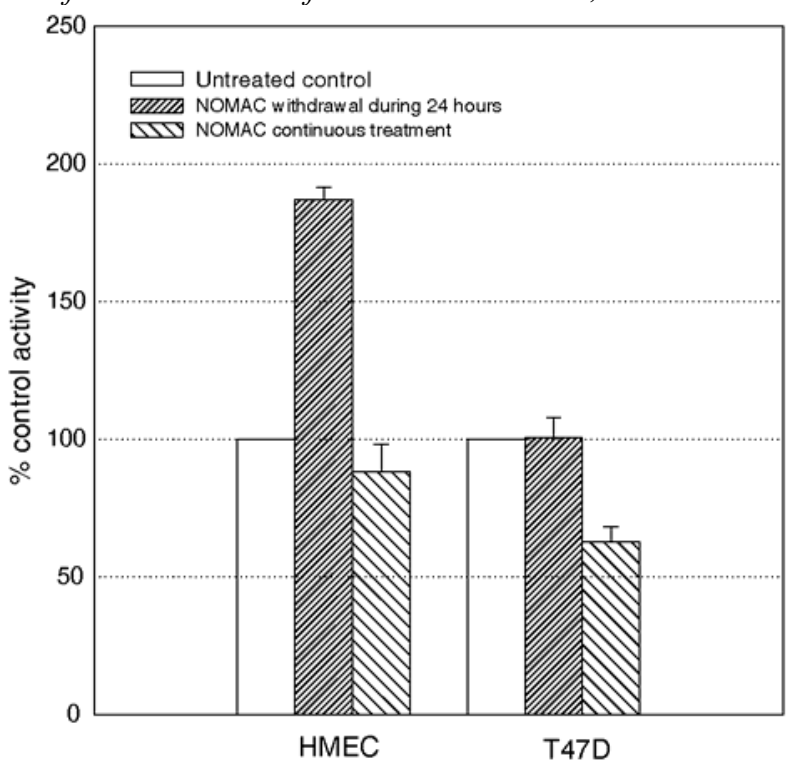

Fig. 4 Effect of NOMAC on apoptosis of T47D cells detected by the TUNEL method. The rates of apoptosis remained low and relatively constant in cultures, whether the cells were untreated, continuously treated with NOMAC or subjected to NOMAC withdrawal, showing a lack of effect of NOMAC on T47D apoptosis in our culture conditions (described in 'Materials and methods').

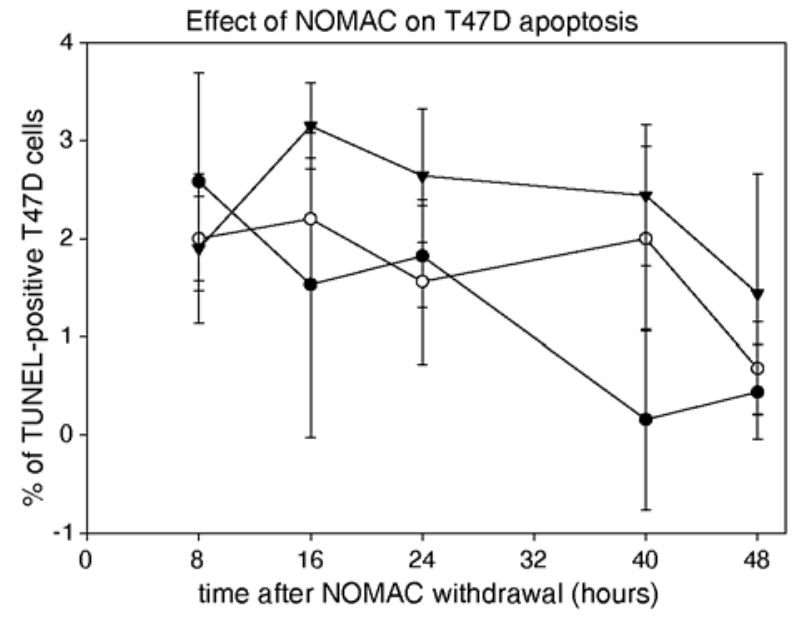

untreated control $-0-$ continuous NOMAC $\rightarrow-$ NOMAC withdrawal

\section{DISCUSSION}

Withdrawal of NOMAC from culture medium of normal HMECs in vitro triggered a marked apoptotic peak $24 \mathrm{~h}$ later, as demonstrated by in situ detection of fragmented DNA (TUNEL) and by measurement of the caspase-3 activity, one of the main enzymes involved in apoptosis. Furthermore, addition of the caspase-3 inhibitor, DEVD-CHO, prevented apoptosis, thereby suggesting a key role for this enzyme in this endocrine regulation of apoptosis. Ferguson and Anderson ${ }^{5}$ previously observed a peak of apoptosis in the normal breast epithelium on day 28 of the menstrual cycle. This phenomenon could play an important part in the maintenance of tissue homeostasis, since it would be implicated in the balance between cell growth and cell death, allowing the cell number to remain constant from one cycle to another. 
Our in vivo study shows that normal breast epithelial cells underwent apoptosis when a hydro-alcoholic gel containing NOMAC was applied once a day for 14 days. According to the protocol, progestin was applied for the last time 24-30 h before surgery. Therefore, it is tempting to speculate that it is the decreased tissular level of NOMAC that is responsible for the induction of apoptosis in the normal breast. In contrast, epithelial cells of fibroadenoma did not respond to this stimulus. The loss of such hormonal regulation of apoptosis could be implicated in the development of fibroadenomas, hyperplasias, and cancers. ${ }^{23,24}$ The data reported by Allan et al. $^{25}$ support this hypothesis, as they showed a reduction of apoptosis relative to mitosis in histologically normal mammary epithelium located near fibrocystic lesions and carcinomas. It is indeed possible that benign epithelial cells of fibroadenoma could escape this hormonal regulation of apoptosis as a result of chronic exposure to various chemokines or cytokines present in the fibroadenomas. Other factors, such as the extracellular matrix and normal stromal cells of the breast, could also be involved in modulating the endocrine induction of mammary epithelial cells apoptosis. ${ }^{26-30}$

The peak of apoptosis induced by NOMAC withdrawal after 3 days of culture did not occur in human mammary T47D tumor cells, despite their constitutive expression of PR. The PR content of T47D, measured by the affinity method, has been shown to be strongly down-regulated by NOMAC after 6 days of continuous treatment. ${ }^{15}$ However, Western blotting (Fig. 1) showed persisting expression of PR protein after 3 days of continuous NOMAC treatment, and in higher amounts than in HMEC cultured in the same conditions. Therefore, the absence of an apoptosis peak in T47-D cells after progestin deprivation cannot be ascribed to a lack of PR. On the contrary, it was continuous treatment with progestins and progesterone that induced apoptosis in T47-D cells, as shown by flow cytometry, morphological analysis, bcl-2 Western blotting, ${ }^{31}$ DNA laddering, and annexin V/propidium iodide staining. ${ }^{32}$ These apparently paradoxical results indicate that the hormonal regulation of apoptosis is altered in malignant cells, a process that could permit and/or promote tumor proliferation.

Entry of the breast cell into G1 phase is necessary to trigger apoptosis, suggesting that proliferation and apoptosis are two different but related biochemical events. Several genes associated with G1 phase, including cyclin D1, D2 and D3 and c-fos, $c-j u n, j u n B, j u n D, c-m y c$, and $p 53$, are induced both in proliferating and in apoptotic mouse mammary tissue. In the clone T47-D-YB, which constitutively expressed the B isoform of PR, a single dose of progesterone accelerates the cells' flux through the first mitotic cell cycle, but arrests or delays them late in G1 phase of the second cycle. Continuous treatment with multiple doses of progesterone chronically inhibits cell growth. In these conditions, progesterone is thus capable of stimulating or inhibiting cell growth, depending on whether treatment is transient or continuous, transient treatment being stimulatory and continuous treatment, inhibitory. ${ }^{33-38}$ The same biphasic effect of progestins on proliferation of normal mammary epithelial cells has been evoked as an explanation for the higher risk of breast cancer in hormone replacement therapy for menopausal complaints when sequential estrogens plus progestin compounds are used than when continuous combined therapy is given. ${ }^{39,40}$ Gompel et al. ${ }^{41}$ observed a proapoptotic effect of continuous exposure of HMEC to Org2058 (another 19-norprogesterone derivative) when the cells were cultured in 1\% of FCS, EGF and insulin. It is indeed plausible that in this 'poor medium,' cell apoptosis would be triggered by exposure to progestin, while in the standard 5\% serum medium culture conditions used here the cells are protected against apoptosis triggered by deprivation conditions. Such protection would not be sufficient to prevent the induction of apoptosis by a stronger stimulus, such as progestin withdrawal from the culture medium in our conditions.

Altogether this in vitro and in vivo study suggests that progestin deprivation contributes to the regulation of apoptosis in normal but not in abnormal breast epithelium.

\section{Acknowledgements}

Normal human breast tissues were kindly provided by Prof. J. Fissette (Plastic Surgery Service of the University of Liège, Belgium) and Dr Van Garsse (St Rosalie Hospital, Liège, Belgium). This work was supported by grants from the Communauté Française de Belgique (Actions de Recherches Concertées), the Commission of European Communities, the Fonds de la Recherche Scientifique Médicale, the Fonds National de la Recherche Scientifique (FNRS, Belgium), the Fédération Belge Contre le Cancer, the C.G.R.I.-F.N.R.S.-INSERM Coopération, the Fonds Spéciaux de la Recherche (University of Liège), the Centre Anticancéreux près l'Université de Liège, the FB Assurances, the Fondation Léon Frédéricq (University of Liège), the D.G.T.R.E. from the Région Wallonne, the Fonds d'Investissements de la Recherche Scientifique (CHU, Liège, Belgium), the Interuniversity Attraction Poles (I.U.A.P.) from the Federal Office for Scientific, Technical and Cultural Affairs (O.S.T.C., Brussels, Belgium), Rhône-Poulenc Rorer Pharmaceuticals (Collegeville, USA) and Roche Diagnostics GmbH (Penzberg, Germany). 
Published in: Breast (Edinburgh, Scotland) (2003), vol. 12, iss. 2, pp. 142-149.

Status: Postprint (Author's version)

\section{References}

1. Dixit V M, Green D R, Reed J C et al. Apoptosis (special section). Science 1998; 281: 1301-1325.

2. Carson D A, Ribeiro J M. Apoptosis and disease. Lancet 1993; 341: 1251-1254.

3. Vogel P M, Georgiade N G, Fetter B F, Vogel F S, McCarty K S. The correlation of histologic changes in the human breast with the menstrual cycle. Am J Pathol 1981; 104: 23-34.

4. Mauvais-Jarvis P, Kuttenn F, Malet C, Gompel A. Antiestrogen action of progesterone in breast tissue. Breast Cancer Res Treat 1986; 8: 179-188.

5. Ferguson D J P, Anderson T J. Morphological evaluation of cell turnover in relation to the menstrual cycle in the "resting" human breast. Br J Cancer 1981; 44: 177-187.

6. Haslam S Z. Progesterone effects on deoxyribonucleic acid synthesis in normal mouse mammary glands. Endocrinology 1988; 122: 464470 .

7. Mark Cline J, Soderqvist G, Von Schoultz E, Lambert S, Von Schoultz B. Effect of hormone replacement therapy on the mammary gland of surgically postmenopausal cynomolgus macaques. Am J Obstet Gynecol 1996; 174: 93-100.

8. Masters R W, Drife J O, Scaribrick J J. Cyclic variation of DNA synthesis in human breast epithelium. J Natl Cancer Inst 1977; 58: 12631265.

9. Adams J M, Cory S. The Bcl-2 protein family: arbiters of cell survival. Apoptosis (special section). Science 1998; 281: $1322-1325$.

10. Sabourin J, Martin A, Baruch J et al. Bcl-2 expression in normal human breast tissue during the menstrual cycle. Int J Cancer 1994; 59: $1-6$.

11. Thompson E B. Apoptosis, steroid hormones. Mol Endocrinol 1994; 8: 665-673.

12. Tenniswood M P, Guenette R S, Lakins J, Mooibroek M, Wong P, Welsh J-E. Active cell death in hormone-dependent tissues. Cancer Metastasis Rev 1992; 11: 197-200.

13. Spencer S J, Cataldo N A, Jaffe R B. Apoptosis in the human female reproductive tract. Obstet Gynecol Surv 1996; 51: 314-323.

14. Catherino W H, Jordan V C. 1Nomegestrol acetate, a clinically useful 19-norprogesterone derivative which lacks estrogenic activity. J Steroid Biochem Mol Biol 1995; 55: 239-246.

15. Botella J, Duranti E, Duc I, Cognet A M, Delansorne R, Paris J. Inhibition of nomegestrol acetate and other synthetic progestins on proliferation and progesterone receptor content of T47-D human breast cancer cells. J Steroid Biochem Biol 1994; 30: 41-47.

16. Soule H D, Mc Grath C M. A simplified method for passage and long term growth of human mammary epithelial cells. In Vitro Cell Dev Biol 1986; 22: 6-12.

17. Gavrieli Y, Sherman Y, Ben-Sasson S A. Identification of programmed cell death in situ via specific labelling of nuclear DNA fragmentation. J Cell Biol 1992; 119: 493-501.

18. Chang K J, Lee T Y, Linares-Cruz G, Fournier S, de Lignières B. Influences of percutaneous administration of estradiol and progesterone on human breast epithelial cell cycle in vivo. Fertil Steril 1995; 663: 785-791.

19. Krajewska M, Wang H-G, Krajewski S et al. Immunohistochemical analysis of in vivo patterns expression of CPP32 (caspase-3), a cell death protease. Cancer Res 1997; 57: 1605-1613.

20. Hasegawa T I, Kamada S, Kamiike W et al. Involvement of CPP32/Yama (-like) proteases in Fas-mediated apoptosis. In Vitro Cell Dev Biol 1996; 56: 1713-1718.

21. Humblet C, Deman J, Franzen R, Greimers R, Boniver J, Defresne M P. Spontaneous and induced apoptosis after whole body radiation exposure: experimental approaches. Observations in radio-induced thymic lymphomagenesis. Stem Cells 1995; 13: $129-135$.

22. Maquoi E, Noel A, Frankenne F, Angliker H, Murphy G, Foidart J M. Inhibition of matrix metalloproteinase 2 maturation and HT1080 invasiveness by a synthetic furin inhibitor. FEBS Lett 1998; 424: 262-266.

23. Glinsky G V, Glinsky V V, Ivanova A B, Hueser C J. Apoptosis and metastasis: increased apoptosis resistance of metastatic cancer cells is associated with the profound deficiency of apoptosis execution mechanisms. Cancer Lett 1997; 115: 185-193.

24. Sheets E E, Yeh J. The role of apoptosis in gynaecological malignancies. Ann Med 1997; 29: 121-126.

25. Allan D J, Howell A, Roberts S A et al. Reduction in apoptosis relative to mitosis in histologically normal epithelium accompanies fibrocystic damage and carcinoma in the premenopausal human breast. J Pathol 1992; 167: 25-32.

26. Meredith J E, Fazeli J B, Schwartz M A. The extracellular matrix as a cell survival factor. Mol Biol Cell 1993; 4: 953-961.

27. Ferguson J E, Schor A M, Howell A, Ferguson M J W. Changes in the extracellular matrix of the normal human breast during the menstrual cycle. Cell Tissue Res 1992; 268: 167-177.

28. Cunha G R. Role of mesenchymal-epithelial interactions in normal, abnormal development of the mammary gland and prostate. Cancer 1994; 74 [Suppl]: 1030-1044.

29. Xie J, Haslam S Z. Extracellular matrix regulates ovarian hormone-dependent proliferation of mouse mammary epithelial cells. Endocrinology 1997; 138: 2466-2473.

30. Boudreau N, Sympson C J, Werb Z, Bissel M J. Suppression of ICE and apoptosis in mammary epithelial cells by extracellular matrix. Science 1995; 267: 891-893. 
31. Kandouz M, Lombet A, Perrot J-Y et al. Proapoptotic effects of antiestrogens, progestins and androgen in breast cancer cells. J Steroid Biochem Mol Biol 1999; 69: 463-471.

32. Formby B, Wiley T S. Progesterone inhibits growth and induces apoptosis in breast cancer cells: inverse effects on Bcl-2 and p53. Ann Clin Sci 1998; 28: 360-369.

33. Sutherland R L, Hall R E, Pang G Y N, Musgrove E A, Clarke C L. Effect of medroxyprogesterone acetate on proliferation and cell cycle kinetics of human mammary carcinoma cells. Cancer Res 1988; 48: 5084-5091.

34. Musgrove E A, Lee C S, Sutherland R L. Progestins both stimulate and inhibit breast cancer cell cycle progression while increasing expression of transforming growth factor alpha, epidermal growth factor receptor, c-fos and c-myc genes. Mol Cell Biol 1991; 11: 50325043.

35. Musgrove E A, Hamilton J A, Lee C S, Sweeney K J, Watts C K, Sutherland R L. Growth factor, steroid and steroid antagonist regulation of cyclin gene expression associated with changes in T47-D human breast cancer cell cycle progression. Mol Cell Biol 1993; 13: 3577-3587.

36. Groshong S D, Owen G I, Grimison B et al. Biphasic regulation of breast cancer cell growth by progesterone: role of the cyclindependant kinase inhibitors p21 and p26 ${ }^{\text {Kip1 }}$. Mol Endocrinol 1997; 11: 1593-1607.

37. Lange C A, Richer J K, Horwitz K B. Hypothesis: progesterone primes breast cancer cells for cross-talk with proliferative or antiproliferative signals. Mol Endocrinol 1999; 13: 829-836.

38. Marti A, Feng Z, Jehn B et al. Expression and activity of cell cycle regulators during proliferation and programmed cell death in the mammary gland. Cell Death Differ 1995; 2: 277-283.

39. Pasqualini J R, Paris J, Sitruk-Ware R, Chetrite G, Botella J. Progestins and breast cancer. J Steroid Biochem Mol Biol 1998; 65: 225235.

40. Hesch R D, Kenemans P. Hormonal prevention of breast cancer: proposal for a change in paradigm. Br J Obstet Gynaecol 1999; 106: 1006-1018.

41. Gompel A, Somaï S, Chaouat M et al. Hormonal regulation of apoptosis in breast cells and tissues. Steroids 2000; 65: 593-598. 